\title{
PRODUÇÃO DE ALFACE APÓS ADIÇÃO DE COMPOSTO E DOSES DE ADUBO NO SOLO
}

\author{
Eduardo Henrique Lima Mazzuchelli ${ }^{1}$; Rita de Cássia Lima Mazzuchelli ${ }^{2}$; Pedro Veridiano Baldotto ${ }^{3}$ \\ Universidade do Oeste Paulista - UNOESTE, Programa de Pós-Graduação em Agronomia, Curso de Graduação em \\ Agronomia, Presidente Prudente - SP. E-mail: eduardomazzuchelli@yahoo.com.br
}

\section{RESUMO}

O objetivo do presente trabalho foi avaliar a adição de composto em proporções com solo e adubo para a produção de alface em reutilização de garrafas pet. O experimento foi conduzido em casa de vegetação localizada no Campus II da Universidade do Oeste Paulista (UNOESTE), no mês de maio de 2014. Para o desenvolvimento do experimento foram utilizadas cinquenta garrafas pet com capacidade para $2 \mathrm{~L}$, o preenchimento de dez garrafas pet caracterizou um tratamento experimental, foram eles: T1- $100 \%$ de compostagem; T2- Mistura 1:1 terra de barranco e compostagem; T3- Mistura 1:1 terra de barranco e compostagem + 0,33 g $\mathrm{g}^{-1} \mathrm{~N}-\mathrm{P}-\mathrm{K}$ 04-14-08; T4Mistura 1:1 terra de barranco e compostagem $+1 \mathrm{~g}^{-1}$ 04-14-08; T5- Mistura 1:1 terra de barranco e compostagem + $3 \mathrm{~g}^{-1}$ 04-14-08. Cada garrafa pet recebeu uma muda de alface var."Vanda" com cerca de 7 dias após a semeadura, que foram obtidas de viveiro comercial. Após 30 dias do transplantio nas garrafas pet, as plantas de alface foram avaliadas quanto ao número de folhas; comprimento de mudas; comprimento de raiz; massa fresca de parte aérea; massa fresca de sistema radicular. As variáveis analisadas foram submetidos ao programa estatístico SISVAR, utilizou-se o teste de Tukey para comparação das médias. Podemos afirmar que a aplicação de 3 gramas de adubo químico (04-14-08) na mistura de compostagem com terra apresentou o maior desenvolvimento do alface cultivado em garrafas pet.

Palavras-chave: Lactuca sativa L.; nutrição de plantas; reutilização de materiais.

\section{LETTUCE PRODUCTION AFTER ADICTION OF COMPOST AND FERTILIZER DOSAGENS ON SOIL}

\begin{abstract}
The objective of this study was to evaluate the addition of compost in with the soil and fertilizer ratios for lettuce production in reusing plastic bottles. The experiment was conducted in a greenhouse located in the Campus II of the Universidade do Oeste Paulista (UNOESTE), in May 2014 for the development of the experiment fifty plastic bottles were used for up to $2 \mathrm{~L}$, filling ten pet bottles featured an experimental treatment, they were: T1 100\% composting; T2-1: 1 Mixture steep bank and composting; T3 Mixture 1: 1 steep bank and composting + $0.33 \mathrm{~g}^{-1} \mathrm{~N}-\mathrm{P}-\mathrm{K}$ 04-14-08; T4-1: 1 Mixture steep bank and compost $+1 \mathrm{~g}^{-1}$ 04-14-08; T5- Mixture 1: 1 steep bank and composting $+3 \mathrm{~g}^{-1}$ 04-14-08. Pet bottle each received a change of lettuce var. "Vanda" about 7 days after sowing, which were obtained from commercial nursery. After 30 days of transplantation in plastic bottles, the lettuce plants were evaluated for the number of leaves; length of seedlings; root length; fresh weight of shoots; fresh weight of the root system. The variables were subjected to statistical SISVAR program, we used the Tukey test for comparison of means. We can say that the application of 3 grams of chemical fertilizer (04-14-08) in the mixture of compost with soil showed the highest development of lettuce grown in plastic bottles.
\end{abstract}

Keywords: Lactuca sativa L .; plant nutrition; reuse of materials. 


\section{INTRODUÇÃO}

A alface é uma hortaliça de grande importância no cenário nacional, sendo a hortaliça mais consumida no país, estando na mesa do consumidor na forma de saladas, na constituição de lanches, sendo seu consumo cada crescente, pois a população com o aumento de renda passa a buscar alimentos mais leves e saudáveis em sua alimentação.

O manejo da cultura deve ser realizado de forma que possibilite que a mesma se desenvolva de maneira eficiente, extraindo os nutrientes necessários para o seu desenvolvimento e, para que complete seu ciclo, que assim como de outras hortaliças é curto, com destino a mesa do consumidor de forma saudável, com o aspecto qualitativo visual.

O consumidor passa a ser cada vez mais exigente com a qualidade do alimento consumido, neste cenário, os alimentos orgânicos passam a despertar o interesse de consumo, já que os mesmos não utilizam produtos químicos em sua produção. Mas desde que as hortaliças sejam cultivadas de maneira eficiente o consumidor passa a procurá-las nas prateleiras do supermercado.

Pelo fato que as pessoas morarem em casas, muitas vezes de espaço reduzido, ou até mesmo apartamentos, dificulta a obtenção de uma área para cultivo de hortaliças, entretanto, algumas medidas podem ser utilizadas para que se cultive uma horta em espaço reduzido, e até mesmo em embalagens que muitas vezes são destinadas ao lixo.

Neste caso, pode-se realizar a reutilização de embalagens de leite longa vida e até mesmo de garrafas pet, estes materiais se destinados ao lixo demoram muitos anos para se decomporem, portanto, reutilizá-los além de obter um destino mais sustentável, ainda contribuem para o aumento na diversidade de alimentos consumidos pela população.

A confecção de hortas em garrafas pet aumenta a sustentabilidade de todo o sistema, por se tratar de um espaço reduzido, as mudas precisam se desenvolver com vigor, portanto, o solo do cultivo necessita fornecer todos os nutrientes necessários para o bom desenvolvimento das plantas, para que as pessoas que consumirem estejam com um alimento de qualidade e cultivado de uma maneira segura.

O objetivo do presente trabalho foi avaliar a adição de composto orgânico em proporções com solo e doses de adubo para a produção de alface em reutilização de garrafas pet. 


\section{METODOLOGIA}

O experimento foi conduzido em casa de vegetação localizada no Campus II da Universidade do Oeste Paulista (UNOESTE) - Faculdade de Ciências Agrárias, em Presidente Prudente - SP, no mês de maio de 2014.

O clima da região é pela classificação de Köppen Aw como mesotérmico com verões quentes e período chuvoso bem definido nos meses de setembro a março e invernos secos com temperaturas mais amenas nos meses de abril a setembro.

Para o desenvolvimento do experimento foram utilizadas cinquenta garrafas pet com capacidade para $2 \mathrm{~L}$, conduzidas nos canteiros da horta, o preenchimento de dez garrafas pet caracterizou um tratamento experimental, foram eles:

T1- 100\% de compostagem

T2- Mistura 1:1 terra de barranco e compostagem

T3- Mistura 1:1 terra de barranco e compostagem + 0,33 $\mathrm{g}^{-1} \mathrm{~N}-\mathrm{P}-\mathrm{K}$ 04-14-08

T4- Mistura 1:1 terra de barranco e compostagem $+1 \mathrm{~g}^{-1} \mathrm{~N}-\mathrm{P}-\mathrm{K}$ 04-14-08

T5- Mistura 1:1 terra de barranco e compostagem $+3 \mathrm{~g}^{-1} \mathrm{~N}-\mathrm{P}-\mathrm{K}$ 04-14-08

Cada garrafa pet recebeu uma muda de alface var. "Vanda" com cerca de 7 dias após a semeadura, que foram obtidas de viveiro comercial. As mudas receberam irrigação periódica, sendo três vezes ao dia, por aspersão instalada no viveiro. O delineamento experimental foi inteiramente casualizado.

Após 30 dias do plantio nas garrafas pet, as plantas de alface foram avaliadas quanto ao:

a) Número de folhas (maiores que $1 \mathrm{~cm}$ )

b) Altura de mudas (cm)

c) Comprimento de raiz $(\mathrm{cm})$.

d) Massa fresca de parte aérea (g)

e) Massa fresca de sistema radicular (g).

As variáveis analisadas para a alface em cada tratamento foram submetidos ao programa estatístico SISVAR, e utilizou-se o teste de Tukey a 1\% de probabilidade para comparação das médias.

\section{RESULTADOS}

A análise de comprimento da parte aérea das plantas de alface, apresentou que todos os tratamentos com a mistura de compostagem com terra mais a adição de dosagens de adubo apresentou maior desenvolvimento das plantas. Sendo assim, pode-se afirmar que a aplicação de 
adubos ao solo com compostagem forneceu mais nutrientes ao solo, proporcionando as plantas um maior desenvolvimento na parte aérea (Tabela 1).

Tabela 1. Comprimento da parte aérea (C.P.A.) em centímetros da alface cultivado em garrafas pet, com combinações de composto com terra e adições de adubos.

\begin{tabular}{ll}
\hline Tratamentos & C.P.A. \\
\hline Compostagem com terra & $12,90 \mathrm{~b}$ \\
Compostagem & $14,90 \mathrm{~b}$ \\
Compostagem com terra e 0,33 N-P-K. & $19,75 \mathrm{a}$ \\
Compostagem com terra e 1,00 N-P-K. & $18,33 \mathrm{a}$ \\
Compostagem com terra e 3,00 N-P-K. & $18,43 \mathrm{a}$ \\
\hline $\mathrm{F}$ & $19,20 * *$ \\
\hline C.V. (\%) & 12,20 \\
\hline${ }^{* *}$ Médias seguidas de mesma letra não diferem estatisticamente pelo teste Tukey (1\%).
\end{tabular}

O comprimento do sistema radicular do alface apresentou um crescimento superior para o tratamento com a utilização de somente compostagem, este tratamento possibilitou o dobro do comprimento do sistema radicular em relação aos demais tratamentos efetuados (Tabela 2).

Tabela 2. Comprimento do sistema radicular (C.S.R.) em centímetros da alface cultivado em garrafas pet, com combinações de composto com terra e adições de adubos.

\begin{tabular}{ll}
\hline Tratamentos & C.S.R. \\
\hline Compostagem com terra & $26,19 \mathrm{~b}$ \\
Compostagem & $41,95 \mathrm{a}$ \\
Compostagem com terra e 0,33 N-P-K. & $21,24 \mathrm{~b}$ \\
Compostagem com terra e 1,00 N-P-K. & $21,05 \mathrm{~b}$ \\
Compostagem com terra e 3,00 N-P-K. & $23,51 \mathrm{~b}$ \\
\hline F & $35,39 * *$ \\
\hline C.V. (\%) & 17,32 \\
\hline
\end{tabular}

**Médias seguidas de mesma letra não diferem estatisticamente pelo teste Tukey (1\%).

Na realização da análise da massa fresca da parte aérea das plantas de alface, evidenciou que todos os tratamentos com a mistura de compostagem com terra mais a adição de dosagens de adubo apresentaram um maior desenvolvimento das plantas. Consequentemente, a aplicação de adubos ao solo com compostagem foi eficiente e forneceu mais nutrientes ao solo, resultando em plantas com maior massa na parte aérea (Tabela 3). 
Tabela 3. Massa fresca da parte aérea (M.F.P.A.) em gramas da alface cultivado em garrafas pet, com combinações de composto com terra e adições de adubos.

\begin{tabular}{ll}
\hline Tratamentos & M.F.P.A. \\
\hline Compostagem com terra & $8,44 \mathrm{~b}$ \\
Compostagem & $12,00 \mathrm{~b}$ \\
Compostagem com terra e 0,33 N-P-K. & $23,72 \mathrm{a}$ \\
Compostagem com terra e 1,00 N-P-K. & $26,80 \mathrm{a}$ \\
Compostagem com terra e 3,00 N-P-K. & $28,32 \mathrm{a}$ \\
\hline F & $47,15^{* *}$ \\
\hline C.V. (\%) & 20,96 \\
\hline$* *$ Médias seguidas de mesma letra não diferem estatisticamente pelo teste Tukey (1\%).
\end{tabular}

Para a variável massa fresca do sistema radicular, o tratamento com a aplicação de 3,00 gramas de adubo ao composto misturado com terra, apresentou maior desenvolvimento do sistema radicular, porém o tratamento que somente houve a mistura de composto com terra apresentou o menor desenvolvimento de raízes (Tabela 4).

Podemos realizar uma comparação com o comprimento do sistema radicular (Tabela 2), o tratamento de compostagem apresentou o maior crescimento de raízes, porém suas raízes cresceram, mas não se desenvolveram em massa do sistema radicular (Tabela 4).

Tabela 4. Massa fresca do sistema radicular (M.F.S.R.) em gramas da alface cultivado em garrafas pet, com combinações de composto com terra e adições de adubos.

\begin{tabular}{ll}
\hline Tratamentos & M.F.S.R. \\
\hline Compostagem com terra & $4,29 \mathrm{c}$ \\
Compostagem & $6,77 \mathrm{~b}$ \\
Compostagem com terra e 0,33 N-P-K. & $5,81 \mathrm{bc}$ \\
Compostagem com terra e 1,00 N-P-K. & $5,97 \mathrm{bc}$ \\
Compostagem com terra e 3,00 N-P-K. & $9,98 \mathrm{a}$ \\
\hline F & $12,52^{* *}$ \\
\hline C.V. (\%) & 28,70 \\
\hline$* *$ Médias seguidas de mesma letra não diferem estatisticamente pelo teste Tukey (1\%).
\end{tabular}

A avaliação do número de folhas, apresentou que o tratamento com a aplicação de 3,00 gramas de adubo ao composto misturado com terra, apresentou maior número de folhas da alface, enquanto que somente a mistura de composto com terra apresentou o menor número de folhas (Tabela 5). 
Tabela 5. Número de folhas (N.F.) da alface cultivado em garrafas pet, com combinações de composto com terra e adições de adubos.

\begin{tabular}{ll}
\hline Tratamentos & N.F. \\
\hline Compostagem com terra & $8,50 \mathrm{c}$ \\
Compostagem & $9,50 \mathrm{bc}$ \\
Compostagem com terra e 0,33 N-P-K. & $10,80 \mathrm{ab}$ \\
Compostagem com terra e 1,00 N-P-K. & $10,90 \mathrm{ab}$ \\
Compostagem com terra e 3,00 N-P-K. & $11,20 \mathrm{a}$ \\
\hline $\mathrm{F}$ & $10,30^{* *}$ \\
\hline C.V. (\%) & 11,07 \\
\hline$* *$ Médias seguidas de mesma letra não diferem estatisticamente pelo teste Tukey (1\%).
\end{tabular}

**Médias seguidas de mesma letra não diferem estatisticamente pelo teste Tukey (1\%).

\section{DISCUSSÃO}

Segundo Heck et al. (2013) a utilização da técnica da compostagem é um recurso empregado com o objetivo de realizar a reciclagem dos resíduos orgânicos e pode ser utilizado nas mais diferentes áreas agrícolas, podendo se obter um composto com propriedades de fertilizante agrícola e/ou corretor de solos degradados, melhorando o desenvolvimento das plantas cultivadas.

A prática da adubação orgânica é recomendada para melhoria da produção de várias culturas, entre elas a alface, que se trata de uma cultura exigente em qualidade de solo e de adubação (VIANA; VASCONCELOS, 2008). De acordo com Oliveira et al. (2014) normalmente no cultivo da alface é bastante comum a utilização de adubação orgânica como forma de suplementação nutricional às plantas. De forma geral, a utilização de compostos à base de resíduos orgânicos em atividades agrícolas é uma alternativa interessante com o objetivo de proporcionar o aumento de produtividade e a redução dos custos com a utilização de fertilizantes químicos e potencializar seus efeitos.

Duarte et al. (2012) constataram que a utilização da dosagem de $45 \mathrm{~m}^{3}$ ha ${ }^{-1}$ de manipueira foi a que propiciou maior ganho de altura de planta, área foliar e, consequentemente, também maior produção de matéria fresca e seca da alface. Assim sendo, o uso da manipueira serviu como fonte de adubação para a cultura da alface, dependendo da dose aplicada.

\section{CONCLUSÃO}

Podemos afirmar que a aplicação de 3 gramas de adubo químico (04-14-08) na mistura de compostagem com terra apresentou o maior desenvolvimento da alface cultivado em garrafas pet. 


\section{REFERÊNCIAS}

ALMEIDA, T.; PRADO, R.; Correia, M. A. R.; Puga, A. P.; Barbosa, J. C. Avaliação nutricional da alface cultivada em soluções nutritivas suprimidas de macronutrientes. Revista Biotemas, v. 24, n. 2, p. 27-36, 2011.

Brasil. Ministério da Agricultura Pecuária e Abastecimento. Secretaria de Defesa Agropecuária. Instrução Normativa n. 25, de 23 de Julho de 2009. Diário Oficial da República Federativa do Brasil. Poder Executivo, Brasília.

CAMARGO FILHO, W. P.; CAMARGO, F. P. Planejamento da produção sustentável de hortaliças folhosas: organização das informações decisórias ao cultivo. Informações Econômicas, São Paulo, v. 38, n. 3, p. 27-36, 2008.

COELHO, A. A.; SILVA, G. L.; ANDRADE, M. B. Q., AUGUSTO, J.; VIRGÍNIO, J. P.; QUEIRÓS, D. R. P. Efeitos da adubação verde, na forma de pré-cultivo, na produção de diferentes cultivares de alface sob manejo agroecológico. Cadernos de Agroecologia, v. 6, n. 2, 2011.

COSTA, C. P.; SALA, F. C. A evolução da alfacicultura brasileira. Horticultura Brasileira, Brasília, v. 23, n. 1, artigo de capa, 2005.

DUARTE, D. S; SILVA, E. F. F.; ROLIM, M. M.; FERREIRA, R. F. A. F.; MALHEIROS, S. M. M.; ALBUQUERQUE, F. S. Uso de diferentes doses de manipueira na cultura da alface em substituição à adubação mineral. Revista Brasileira de Engenharia Agricola e Ambiental-Agriambi, v. 16, n. 3, 2012.

FIGUEIREDO, C. C.; RAMOS, M. L. G.; McMANUS, C. M.; MENEZES, A. M. Mineralização de esterco de ovinos e sua influência na produção de alface.

Horticultura Brasileira, v. 30, p. 175-179, 2012.

HECK, K.; ;MARCO, É. G.; HAHN, A. B.; KLUGE, M.; SPILKI, F. R.; VAN DER SAND, S. T. Temperatura de degradação de resíduos em processo de compostagem e qualidade microbiológica do composto final. Revista Brasileira de Engenharia Agrícola e Ambiental, v. 17, n. 1, p. 54-59, 2013.

LEAL, M. A. A.; GUERRA, J. G. M.; ESPINDOLA, J. A. A.; ARAÚJO, E. S. Compostagem de misturas de capim-elefante e torta de mamona com diferentes relações C: N. Revista Brasileira de Engenharia Agrícola e Ambiental, v. 17, n. 11, p. 1195-1200, 2013.

OLIVEIRA, A. S.; ARAUJO, A. M. N.; ZELARAYÁN, M. L. C.; MELO, D. M.; SILVA, M. R. M. Eficiência de diferentes compostos orgânicos como método alternativo no desenvolvimento da alface (Lactuca sativa L.). Cadernos de Agroecologia, v. 6, n. 2, 2011.

OLIVEIRA, L. B.; ACCIOLY, A. M.; SANTOS, C. L.; FLORES, R. A.; BARBOSA, F. S.

Características químicas do solo e produção de biomassa de alface adubada com compostos orgânicos. Revista Brasileira de Engenharia Agrícola e Ambiental, v. 18, n. 2, p. 157-164, 2014.

PEREIRA, R. A.; FARIAS, C. A.; RÊGO, E. T.; PEDROSA, T. D.; CHAVES, A. D. C. A. Compostagem como alternativa para a problemática dos resíduos agroindustriais no Sertão Paraibano. Revista Verde de Agroecologia e Desenvolvimento Sustentável, v. 8, n. 1, p. 269-273, 2013. 
PORTO, V. C. N.; SANTOS, E. C.; FERREIRA, L. L.; SILVA, J. R.; ALENCAR, R. D. Componentes nutricionais de cultivares de alface em sistema orgânico de produção na região do Semiárido Potiguar. Cadernos de Agroecologia, v. 8, n. 2, 2013.

SILVA, H. D.; CARDOSO, A. M. S.; SOUZA, V. B.; CRUZ, M. D. D. S.; CARMO, P. C. O.; CUNHA, L. M. V. Viabilidade Agronômica de Consórcios entre Alface e Rúcula no Sistema Orgânico de Produção. Cadernos de Agroecologia, v. 6, n. 2, 2011.

SILVA, P. R. D.; LANDGRAF, M. D.; REZENDE, M. O. O. Processo de estabilização de resíduos orgânicos: vermicompostagem versus compostagem. Quimica Nova, v. 36, n. 5, p. 640-645, 2013.

VIANA, E. M.; VACONCELOS, A. C. F. Produção de alface adubada com termofosfato e adubos orgânicos. Revista Ciência Agronômica, Fortaleza, v. 39, n. 02, p. 217-224, Abr.- Jun., 2008 